\title{
Jornal escolar no ensino fundamental: análise crítica de gênero
}

\author{
School newspaper at elementary school: \\ genre critical analysis at elementary school
}

Vanessa Wendhausen Lima ${ }^{2}$

Faculdade SATC

DOI: https://doi.org/10.5902/2176148534761

Resumo: O objetivo deste trabalho é analisar, do ponto de vista da Análise Crítica de Gênero (BONINI, 2011), a relação entre gênero e prática social em jornal escolar produzido por alunos de uma turma do ensino fundamental de uma escola pública estadual de SC. Os resultados sugerem que a prática social influencia a produção do gênero jornal escolar e não pode ser excluída do processo de análise genérica. 0 jornal escolar demonstra que a escola deve se posicionar para além do estabelecimento de regras de ensino e entender que as influências extraescolares podem estar bem mais presentes do que se previa.

Palavras-Chave: Jornal Escolar. Prática Social. Análise Crítica do Gênero.

Abstract: The objective of this study is to analyze, from the point of view of the Genre Critical Analysis (BONINI, 2011), the relationship between gender and social practice in a school newspaper produced by students of a class of SC's elementary school. The results suggest that social practice influences the production of the school newspaper genre and cannot be excluded from the generic analysis process. The school newspaper demonstrates that the school must position itself beyond the establishment of rules of teaching and understand that extracurricular influences may be far more present than anticipated.

Keywords: School Newspaper. Social practice. Genre Critical Analysis.

1 Este trabalho é um excerto da tese de doutorado da autora e foi orientada pelo professor doutor Adair Bonini, na Universidade do Sul de Santa Catarina, em convênio com a Universidade Federal de Santa Catarina. 2 Doutora em Ciências da Linguagem. Professora dos cursos de Design Gráfico, Jornalismo e Publicidade e Propaganda da Faculdade SATC - Criciúma/SC. e-mail: vanessa.wendhausen@satc.edu.br 


\section{Introdução}

Desenvolver a escrita em ambiente escolar tem se mostrado uma tarefa árdua para professores e alunos. Isso tem acontecido, possivelmente, não só pela forma como as novas gerações tem lidado com seu próprio aprendizado ou com o gerenciamento do alto fluxo de informação com o qual convivem, mas também por entenderem que os métodos de ensino já não se mostram eficientes em comparação com o acesso fácil ao banco de dados da internet.

Vanessa

No entanto, todo o acesso à informação não será suficiente se o

Wendhausen

Lima indivíduo não souber o que fazer com isso. Tendo em vista que o funcionamento da escrita não se refere apenas aos aspectos do "saber ler e escrever", mas que está mais para o domínio do funcionamento da linguagem como um todo, um dispositivo social que produz sentido mediante as atividades dos sujeitos, modifica-se e influencia os aspectos da vida social, é relevante refletir sobre essa dinâmica de existência da linguagem. Contudo, é preciso entender que linguagem "em movimento" é discurso e uma das formas de manifestações discursivas é o gênero.

O gênero sofre e apresenta influências diversas, entre elas, a exercida pelo discurso que, por sua vez, pode ser considerado um dos momentos da prática social, aquela que movimenta e regula o funcionamento da sociedade. 0 momento da produção de um gênero não pode ser suficientemente entendido se a análise estiver limitada ao textual.É preciso considerar as relações dialógicas que envolvem o gênero e, sobretudo, quais os aspectos dessas relações influenciam e se manifestam na produção.

Pensando nesses aspectos, uma análise crítica de gênero deve ir além do textual, tomando como central a relação entre o gênero e a prática social. Essa relação é um dos aspectos centrais do quadro teórico-metodológico da Análise Crítica de Gênero (BONINI, 2011), que fundamenta essa pesquisa e evidencia a necessidade de uma visão crítica perante a relação linguagem-sociedade, assumindo uma perspectiva de "crítica" discursiva utilizando-se de pressupostos pertencentes ao quadro teórico da Análise Crítica do Discurso, de Fairclough (2008/1992, 2003) e de alguns aspectos do enunciado e dos Gêneros do Discurso, de Bakhtin (2004/1979, 2011/1953).

Esta pesquisa toma o gênero jornal escolar como objeto de ensino e de análise, incentivando o protagonismo escolar, abrindo espaço para a autoria discente e para a educação crítica. Produzido por uma 
turma de correção de fluxo ${ }^{3}$ dos anos finais do ensino fundamental de uma escola pública estadual do município de Tubarão, SC, este jornal escolar se configura como um projeto de letramento.

\section{Análise crítica do gênero}

De acordo com Lima (2014), é possível perceber que a Análise Crítica de Gêneros, conforme proposto por Bonini (2011), se apresenta como um quadro teórico-metodológico que busca entender a dinâmica de funcionamento dos gêneros. Isso significa pensar, também, naquilo que influencia os gêneros que circulam socialmente, quais

Jornal escolar no ensino fundamental

Gêneros não surgem do vazio, mas sempre de uma relação de interação com outros gêneros e com outros aspectos do contexto que abrigam esses gêneros. Responsáveis por organizar a comunicação humana, o funcionamento dos gêneros depende tanto de outros gêneros, quanto das estruturas que regulam sua circulação e, por consequência, da forma como os sujeitos estabelecem contato com esses gêneros. Os sujeitos, por sua vez, só têm a possibilidade de conhecer e de dominar a utilização dos gêneros, porque os gêneros contam com suportes físicos e sociais que permitem sua existência e sua circulação social.

Segundo Bonini (2011), os gêneros se constituem através de relações dialógicas e interdependentes estabelecidas com outros gêneros, com as práticas sociais e discursivas, com as estruturas sociais e com o discurso. Essas relações podem estar restritas ao campo do enunciado ou ampliadas ao âmbito do discurso e das estruturas sociais.

Os sujeitos produtores/receptores envolvidos com o gênero estão envolvidos também em uma série de ações que podem ser relativas às ações de produção, ações de compreensão e ações de textualização. Tais ações dizem respeito àquilo que os sujeitos produtores/receptores precisam acionar quando chamados à produção, textualização e compreensão de um gênero, por exemplo: os conhecimentos sobre o gênero e seus objetivos; o conhecimento de mundo necessário para a

3 Por turmas de correção de fluxo denominam-se projetos das secretarias estaduais de educação que têm por objetivo corrigir a disparidade idade/série de alunos matriculados nos anos finais do ensino fundamental. Essas turmas costumam reunir estudantes que apresentaram histórico de reprovações e, por isso, apresentam também uma idade superior aos colegas de turmas regulares. 
textualização ou a identificação do público receptor e do que ele espera compreender desse gênero. Essas ações provocam um resultado a que se pode chamar de prática social do gênero.

O gênero está imerso em práticas sociais que lhe são inerentes e que determinam sua forma, seu conteúdo, a maneira como os sujeitos o (re)produzem e o compreendem. Essa relação dialógica é um fator constitutivo do gênero, evidenciando que um gênero está sempre conectado a outro, que uma prática discursiva está sempre ligada à outra, interfe-

Vanessa

Wendhausen

Lima rindo-se e influenciando-se mutuamente. Para entender o gênero sob esse viés, é preciso entender como essas relações se estabelecem como fortes influências na formação do gênero e do discurso.

Essa relação de constituição é essencial, pois, em alguns casos, os gêneros nem existiriam se não fossem alguns elementos (o suporte e a mídia, por exemplo), isto é, sem esses, os gêneros não poderiam circular ou seriam completos desconhecidos dos sujeitos. Essa relação de interação entre os gêneros e esses elementos, segundo Bonini (2011), pode ser chamada de relação genérica e podem ocorrer de quatro formas: com o hipergênero, com a mídia, com o sistema de gêneros e com a comunidade discursiva.

$O$ gênero pode se relacionar com um hipergênero, uma espécie de agrupamento de gêneros, onde as produções genéricas simplesmente acontecem em conjunto. Conforme Bonini (2011, p. 691), essa produção pode ocorrer num agrupamento, que permite formar "uma unidade de interação maior (um grande enunciado)", como o jornal, por exemplo. A mídia, por sua vez, é uma "forma tecnológica material de mediação da interação linguageira, sendo que ela constitui-se de um ou mais suportes e apresenta uma forma característica de organização, produção e recepção" (BONINI, 2011, p. 693). A relação com a mídia é essencial, tendo em vista que, segundo o autor, é a mídia que põe o gênero em circulação e, ainda, organiza os sujeitos produtores/receptores através do cenário espaço-temporal dos gêneros. Ainda segundo o autor, "gêneros e hipergêneros se ajustam às formas de produção e recepção possibilitadas pela mídia”. Os gêneros, com suas práticas discursivas, tanto quanto os sujeitos que os produzem/ recebem, precisam se ajustar às possibilidades midiáticas para que possam entrar e se manter em circulação social. Por isso, esta é outra das relações que constituem e, de alguma forma, determinam o gênero.

Quanto ao sistema de gêneros, conceito proposto por Bazerman (2006), Bonini (2011, p. 693) declara que "os gêneros podem ser vistos como elementos de uma sequência de práticas e ações sociais [...] [em 
que] um gênero cria condições para existência de outro". Já no que se refere à comunidade discursiva, conceito proposto por Swales (1990), "os gêneros em uma comunidade discursiva, estão a serviço de uma hierarquia de membros que, juntos, realizam um conjunto de práticas sociais também hierarquizadas" (BONINI, 2011, p. 693).

Outro possível nível de análise, conseguinte às relações genéricas, refere-se às relações do plano do discurso. Para o autor, gêneros são materializações do discurso, assim como as práticas sociais imersas nos gêneros também influenciam os discursos. Por último, aparecem as relações no plano da estrutura social. "As instituições (como a igreja, a economia e a ciência) constituem tanto os discursos quanto as práticas sociais e são, ao mesmo tempo, por esses constituídas" (BONINI, 2011, p. 694).

Segundo Bonini, seu quadro conceitual permite, quando obserJornal escolar no ensino fundamental vado numa perspectiva ascendente, a possibilidade de uma análise que parta do gênero rumo ao discurso, construindo uma análise crítica de gêneros. $O$ contrário também é possível: numa perspectiva descendente, permite construir um caminho para a análise crítica do discurso. Ao optar pela análise crítica de gêneros como fundamento teórico-metodológico para este trabalho, entendo a necessidade de traçar uma rota possível que vá além do textualmente explícito e busque identificar e refletir sobre as assimetrias de poder que influenciam a constituição dos gêneros e dos discursos.

\section{0 gênero jornal escolar}

Há três possibilidades de definição para o jornal: como um suporte textual, como uma mídia (devido ao seu status social adquirido) ou como um gênero. Para se definir o jornal como um gênero (pensamento assumido neste trabalho) é preciso elencar os aspectos em que se baseia essa caracterização. De acordo com Bonini (2008, p. 35) "há motivos para se considerar o jornal um gênero [...] porque [este] preenche quesitos como propósitos comunicativos próprios, organização textual característica e produtores e receptores definidos". Partindo desse pensamento, classifico o jornal escolar como um gênero por encontrar nas edições analisadas algumas das características elencadas.

O propósito comunicativo do jornal escolar é um dos itens que permitem fomentar regularidades que o caracterizem como gênero. Num jornal convencional, basicamente, seu propósito comunicativo está relacionado, conforme Bonini (2001), às ações de noticiar, opinar, 
criticar. Esse propósito pode ser tomado como um dos aspectos que permite a identificação de um jornal como tal. É preciso ressaltar que a utilização do conceito "propósito comunicativo" vem de Bonini (2001, 2008) e, assim como o autor não utiliza esse conceito em seus trabalhos mais recentes, este trabalho também não pretende fazer referência aos estudos da área que veem o gênero como realizador de um propósito comunicativo.

No que se refere ao jornal escolar, opto por pensar em "objetivo"

Vanessa

Wendhausen

Lima

116 do gênero jornal escolar que é, além de se configurar como um instrumento de ensino e de aprendizagem, é promover a interação discente e incentivar os estudantes a assumirem uma posição mais central em seus processos de aprendizagem escolar. Em essência, o objetivo desse gênero, apesar de algumas vezes parecer se perder ao longo da produção, é incentivar a prática de escrita autoral pelos estudantes. No entanto, não é difícil destacar que o jornal escolar possa assumir alguns aspectos que contemplam os mesmos propósitos comunicativos do jornal convencional, como noticiar, criticar ou opinar, entretanto, um objetivo ideal para o jornal escolar é dar prioridade à interação discente, a fim de evitar que a produção se torne escolarizada.

Além do propósito comunicativo, um jornal pode ser considerado um gênero por apresentar uma organização textual característica que pode ser encontrada em diversos exemplares de jornal (escolares ou convencionais). Esta organização pode ser marcada pela presença de itens como o cabeçalho, a chamada, a manchete e/ou a fotografia. Esses itens dispostos e agrupados num conjunto de páginas que formam uma unidade costumam levar a uma identificação no público consumidor: trata-se de um jornal. Tem sido possível perceber que essas características podem ser estendidas ao jornal escolar, tendo em vista que esse último ainda busca se legitimar como jornal escolar, ao assumir características comuns ao jornal convencional.

Outro aspecto que permite que o jornal seja pensado como um gênero é o fato de que este serve como um agregador de outros gêneros. É um aspecto que, além de definir sua organização característica, o estabelece como um jornal, pois este não seria um jornal se não trouxesse notícias ou reportagens, se não apresentasse um cabeçalho ou um expediente, se não tivesse um caderno (de algum tema específico, como o de esportes ou o de classificados) ou a seção de carta do leitor. A presença recorrente desses gêneros faz do jornal um hipergênero, isto é, um gê- 
nero que abriga outros gêneros. Esses gêneros agrupados, assim como outros itens presentes no jornal, tais como os aparatos de edição, são os responsáveis por fornecer uma organização textual característica e, por isso, permitem sua identificação não apenas como um jornal, mas como um hipergênero. No quadro a seguir, é possível ver os gêneros e aparatos elencados por Bonini (2008) como elementos frequentes no jornal.

\begin{tabular}{|c|c|c|c|}
\hline \multicolumn{2}{|c|}{ Gêneros } & \multicolumn{2}{|c|}{ Aparatos de Edição } \\
\hline $\begin{array}{l}\text { Presos: } \\
\text { Editorial } \\
\text { Carta do leitor } \\
\text { Expediente } \\
\text { Chamada } \\
\text { Índice } \\
\text { Cabeçalho }\end{array}$ & $\begin{array}{l}\text { Livres: } \\
\text { Notícia } \\
\text { Nota } \\
\text { Crítica } \\
\text { Comentário } \\
\text { Opinião } \\
\text { Reportagem } \\
\text { Entrevista } \\
\text { Claquete }\end{array}$ & $\begin{array}{l}\text { Manchete } \\
\text { Lide } \\
\text { Lista } \\
\text { Painel } \\
\text { Chapéu } \\
\text { Olho } \\
\text { Tabela } \\
\text { Gráfico } \\
\text { Citação }\end{array}$ & $\begin{array}{l}\text { Exemplo } \\
\text { Perfil } \\
\text { Selo }\end{array}$ \\
\hline
\end{tabular}

Jornal escolar no ensino fundamental

Figura 1 - Gêneros e aparatos de edição do jornal; Fonte: Bonini, 2001.

Este jornal escolar pode ser caracterizado como gênero porque apresenta alguns dos elementos acima. Um primeiro aspecto a ser considerado é a presença de itens de paginação. A inserção de números de página na publicação auxilia a transformar uma coleção independente de textos e folhas em uma unidade caracterizada por um projeto de dizer.

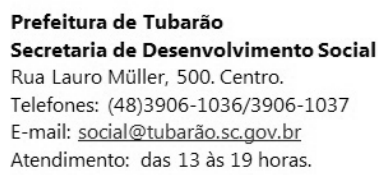

Figura 2 - Exemplo de paginação do Jornal 803 Intensivo;

Fonte: Edição n.1 do jornal 803 Intensivo publicada em julho de 2012, pelos alunos da turma de correção de fluxo, 803 Intensivo.

Os gêneros que aparecem nessas edições auxiliam a configurar sua organização textual e a concretizar sua definição como hipergênero. Esses gêneros são característicos ao jornal, isto é, aparecem em produtos relacionados ao jornalismo e, geralmente, em locais fixos, a fim de permitir, também, o reconhecimento do público consumidor. Além disso, essa tipificação, pela qual o gênero passou, faz com que o sujeito, ao pensar em produzir jor- 
nal, atribua a ele um aspecto visual recorrente em outros jornais, algo que auxilia no processo de constituição e estruturação do jornal. Um aspecto que permite configurar esta produção como gênero jornal é o cabeçalho:

\section{JORNAL 803 INTENSIVO}

Jornal-piloto produzido pela Turma 803 Intensivo da Escola Célia Coelho Cruz.

Figura 3 - Cabeçalho do Jornal 803 Intensivo;

Vanessa Fonte: Edição n. 1 do jornal 803 Intensivo publicada em julho de 2012, pelos alunos da

Wendhausen

Lima

turma de correção de fluxo, 803 Intensivo.

O cabeçalho costuma aparecer na capa, no topo da página e de maneira que o público consumidor possa percebê-lo imediatamente. 0 cabeçalho é constituído de informações sobre o jornal, como o título, a data da publicação, o número da edição e a marca de referência (o logotipo) da publicação. No caso do jornal escolar, informa quem esteve envolvido com a produção e traz a informação sobre a escola a que pertencem os produtores dos textos publicados. Neste, produzido pela turma 803 Intensivo, o cabeçalho faz referência ao nome da turma e se repete na segunda edição, conforme figura abaixo:

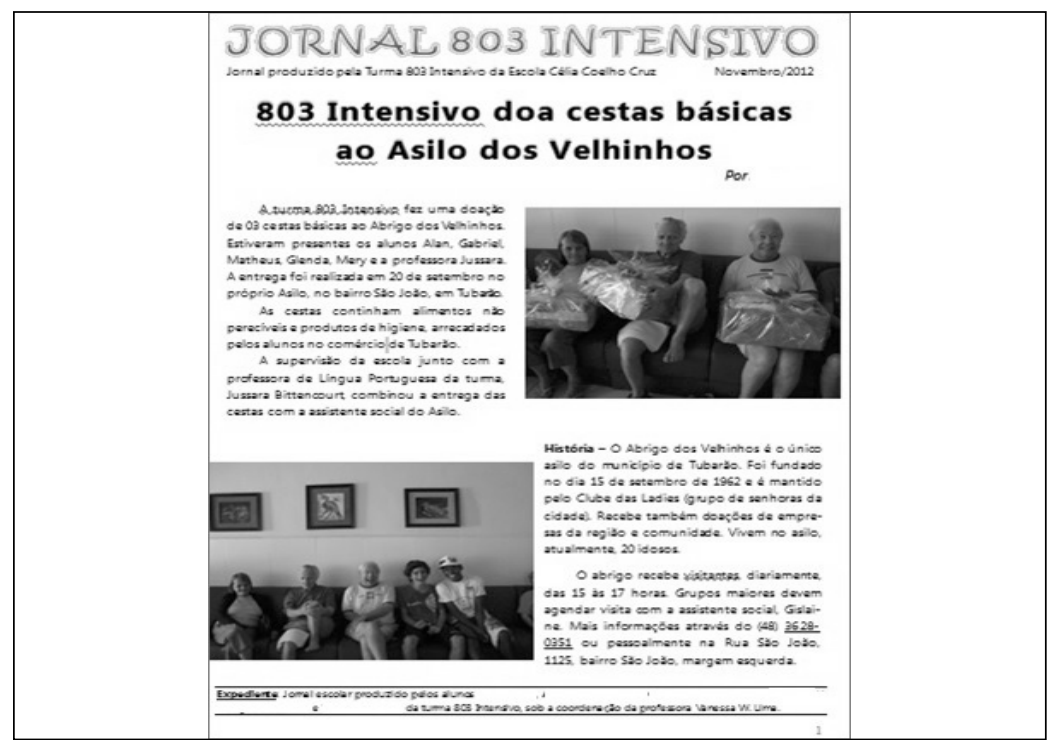

Figura 4 - Cabeçalho da segunda edição do Jornal 803 Intensivo; Fonte: Primeira página da edição n. 2 do jornal 803 Intensivo publicada, em novembro de 2012, pelos alunos da turma de correção de fluxo, 803 Intensivo. 
Outro gênero que aparece no hipergênero jornal, é o expediente. Presente nos jornais convencionais, o expediente é formado por um conjunto de informações que identificam o jornal, tais como: a listagem da equipe da redação (ao menos a direção, as chefias e as editorias), os dados de tiragem e de circulação, os endereços e telefones para contato sobre assinaturas e edições anteriores. No jornal escolar, por não ser comercializado (ao menos neste caso), não há informações como telefone de contato para assinaturas ou dados de tiragem. Nessas edições do jornal 803 Intensivo, o expediente também está presente, porém as informações que o constituem, limitam-se a identificar os alunos produtores ${ }^{4}$ dos textos e o professor responsável pela publicação. Nas duas edições, ele aparece conforme figuras 5 e 6, a seguir:

\section{Jornal escolar no ensino fundamental}

Expediente: Projeto de jornal escolar produzido pelos alunos da Turma 803 Intensivo:

Professora Responśávet Vanessa W Lima

Figura 5 - Expediente do Jornal 803 Intensivo; Fonte: Edição n. 1 do jornal 803 Intensivo publicada em julho de 2012, pelos alunos da turma de correção de fluxo, 803 Intensivo.

Na primeira edição, o expediente está localizado na página $4 . \mathrm{Na}$ segunda, o expediente pode ser encontrado logo na página 1 , de acordo com figura 6 abaixo:

Expediente: Jornal escolar produzido pelos alunos

da turma 803 Intensivo, sob a coordenação da professora Vanessa W. Lima.

Figura 6 - Expediente da segunda edição do Jornal 803 Intensivo; Fonte: Edição n. 2 do jornal 803 Intensivo publicada em novembro de 2012, pelos alunos da turma de correção de fluxo, 803 Intensivo.

Outros dois gêneros comuns ao jornal e que também aparecem neste jornal escolar são a notícia e a reportagem. A notícia tem, segundo Bonini (2008, p. 37), "o propósito de relatar um fato/acontecimento". A definição de reportagem, por sua vez, depende de se olhar para o que é mais característico: a reportagem enfoca assuntos e não eventos.

É possível encontrar nessas edições, alguns exemplos de notícia e de reportagem, mesmo que o ensino desses gêneros não tenha sido contemplado no projeto e, sobretudo, não tenham servido de referência para as produções textuais. A presença desses dois gêneros no jornal escolar é um dos motivos para que o jornal seja considerado um hipergênero.

4 Os nomes dos estudantes foram removidos a fim de preservar suas identidades. 


\section{Intensivo doa cestas básicas ao Asilo dos Velhinhos}

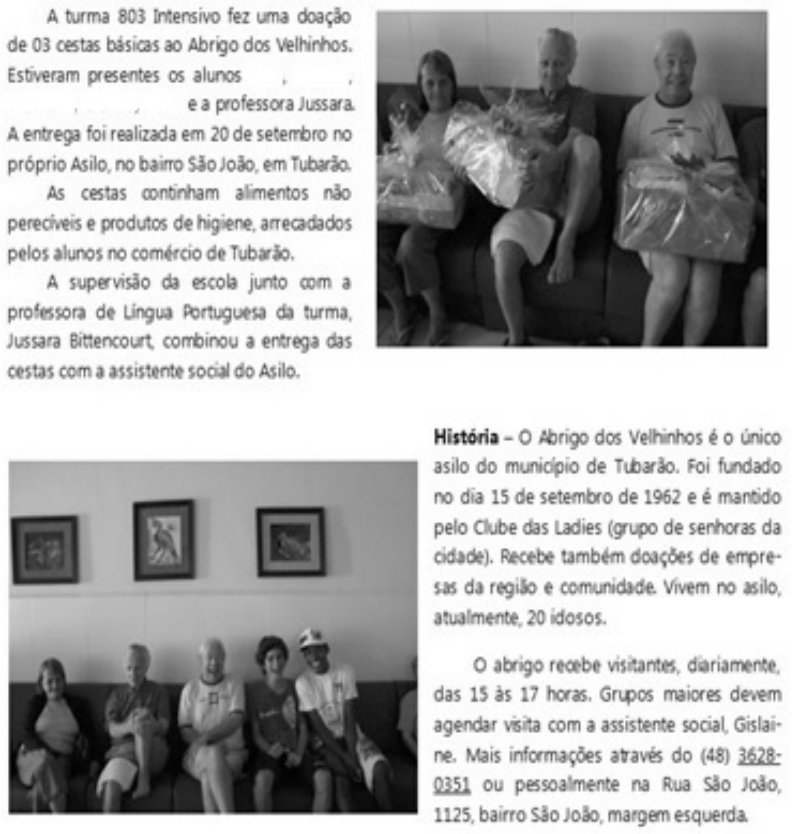

A turma 803 intensivo fez uma doaçă de 03 cestas básicas a Abrigo dos Velhirhos. Estiveram presentes os alunos

e a professora Jussara. A entrega foi realizada em 20 de setembro no

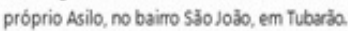

As cestas continham alimentos n30 pereciveis e produtos de higiene, arrecadados pelos alunos no comercio de Tubario.

A supervisão da escola junto com a professora de Lingua Portuguesa da turma, Jussara Bittencourt combinou a entrega das cestas com a assistente social do Asilo.

História - O Abrigo dos Velhinhos é o único asilo do municipio de Tubarado. Foi fundado no dia 15 de setembro de 1962 e é mantido pelo Clube das Ladies (grupo de serhoras da cidade). Recebe tamberm doaçóbs de empresas da regibo e comunidade. Vivem no asilo, atualmente, 20 idosos.

0 abrigo recrbe visitantes, dariamente. das 15 as 17 horas, Grupos maiores devem agendar visita com a assistente social, Gislaine. Mais informaçōes através do (48) 3628 Q351. ou pessoalmente na Rua Săo Jodo, 1125 , bairro Săo jol̉o, margem esquerda.

Figura 7 - Exemplo de notícia publicada no Jornal Escolar 803 Intensivo; Fonte: Edição n. 2 do jornal 803 Intensivo publicada em novembro de 2012, pelos alunos da turma de correção de fluxo, 803 Intensivo.

Considerando que uma notícia é, em essência, o relato de um fato/acontecimento, este texto pode ser configurado como o relato de uma coleta e doação de cestas básicas que a turma produtora do jornal realizou no mesmo período da produção da edição. Entretanto, a motivação que levou a tal publicação pode não ter sido o interesse do público leitor pelo assunto. Talvez seja possível pensar que esse interesse pelo tema tenha vindo mais do público produtor, tendo em vista que são eles mesmos os autores da doação. Entretanto, como a questão central aqui é a presença de gêneros que justifiquem a conceituação do jornal como um hipergênero, a relevância da publicação não é algo a ser considerado no momento.

No que se refere à presença do gênero reportagem, nessas duas edições de jornal escolar podem ser encontrados alguns exemplos de reportagens didáticas. No entanto, antes mesmo de elencar alguns desses 
textos, é preciso destacar que as reportagens produzidas para o jornal 803 Intensivo não serviram como instrumento de ensino do gênero jornalístico reportagem. Conforme dito anteriormente, esta produção de jornal escolar não contemplou o ensino de gêneros jornalísticos. Mas, ainda assim, é possível descrever os textos publicados como semelhantes a reportagens didáticas, tendo em vista que as produções textuais publicadas buscam "explicar um assunto, situação problema ou serviço" (BONINI, 2008, p. 37). Nas figuras 8 e 9, encontramos as reportagens didáticas produzidas para as duas edições do Jornal 803 Intensivo:

Jornal escolar no ensino

Trabalho na adolescência

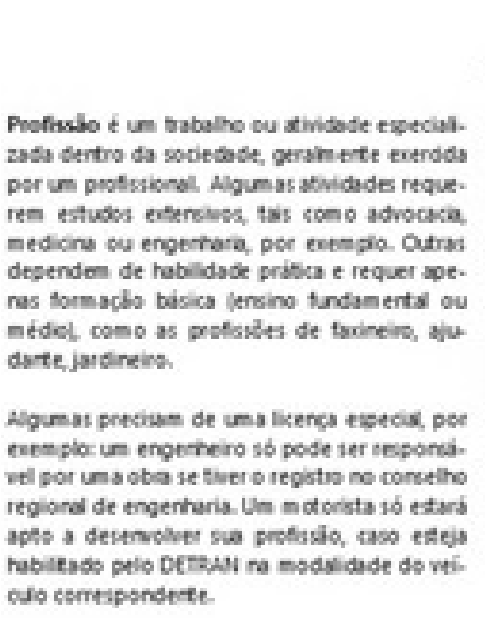

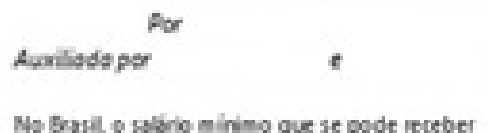

fundamental

\section{Sou estudante. Quero trabalhar. $O$ que faço?}

Woci pede procurar programas de aptendiagem que ajudam a encortra e agrencer una profissba. Weja abaiso onde voct pade encortrar algurs destet pesoramas

\section{Pretpiture de Tuberis}

Secretarla de Desemolvimento Social

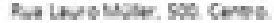

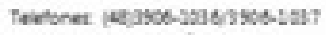

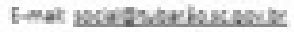

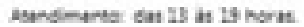

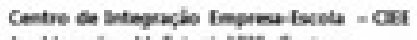

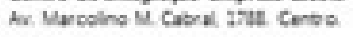

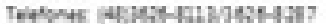

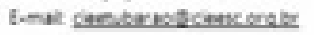

\section{Ainds ten sividont}

Fale com unu de nowus erientudorat ebou vortet

Figura 8 - Exemplo de reportagem didática publicada no Jornal 803 Intensivo; Fonte: Reportagem didática publicada na página 1 da edição n. 1 do Jornal 803 Intensivo publicada em julho de 2012, pelos alunos da turma de correção de fluxo, 803 Intensivo. 


\section{Jogue futebol: faz bem å saúde}

Vanessa

Wendhausen

Lima
$\mathrm{T}$ odo mundo fala que a gente tem que fazer atividade fisica, mas nem sempre a gente tem dinheiro pra pagar uma academia. Hoje vamos falar de uma atividade que pode ser de graç: o futebol. O futebol é um dos esportes mais populares do mundo.

O futebol tornou-se popular graças a seu jeito de jogar: basta uma bola, equipes de jogadores e as traves, para que, em qualquer espaço, crianças e adultos possam se divertir com o futebol Na rua, na escola, no clube, no campinho do bairro ou atế mesmo no quintal de casa, desde cedo jovers de vários cantos do mundo aprendem a jogar bola.

O futebol pode ser jogado de várias maneiras: em quadras de saläo ou suico, e em campos naturas. Pra jogar futebol de areia, saläo ou sulço você precisa apenas de 5 pessoas. Para jogar futebol você precisa fazer alguma atividade fisica como se alongar após a partida de futebol.

\section{Os benefícios do futebol para o corpo}

Para termos saúde, precisamos praticar alguma atividade fisica. Mas nem sempre temos dinheiro ou tempo para irmos a uma academia. Você sabia que existem atividades físicas que são gratis e bem fáceis de prasicar. 0 futebol é uma dessas.

Prasicar esporte traz muitos beneficios à saúde e o futebol năo fica atrás. Outra vantagem de praticar este esporte é ficar com perras fortes e bonitas. Alem disso, o futebol pode ajudar na diminuiçăo de gordura localizada, na manutença do peso e no aumento da densidade óssea, melhora da resistència cardiovascular.

\section{Os perigos do sedentarismo}

Quando nà̃o praticamos exercicios físicos e deixamos o sedentarismo tomar conta de nosso corpo, a capacidade de respiracilo pro. funda diminui e o coraço e a circulaça do sangue para tecidos e órgảos também deica de funcionar adequadamente. Basta um pouco de esforç para ficar rapidamente cansado e sentir dificuldade até mesmo na execuça das tarefas diarias.

\section{Mexa-se!}

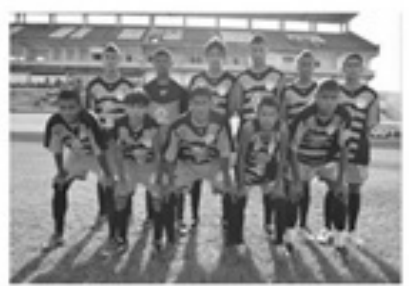

Primeiro, visite um módico e faç um exame fisico com detalhes para verificar possiveis problemas de saúde.

Depos, com a ajuda de um profissional de educaço f́sica, faç uma avaliaçảo partiIhando com ele seus cbjetivos e necessida. des. A partir disso é que se pode definir 0 plano de exercicios adequado.

É preciso ter regularidade e se exercitar por 30 minutos pelo menos tris vezes por semana. Em atividades, como a musculaç̄o, caso o treino seja dário será preciso dividir os grupos musculares para năo sobre carregar. Näo adianta dar o máximo em um dia, e nos próximos quatro dias nlo se exercitar.

Figura 9 - Exemplo de reportagem didática publicada no Jornal 803 Intensivo; Fonte: Reportagem didática publicada na página 2 da edição n. 1 do Jornal 803 Intensivo publicada em julho de 2012, pelos alunos da turma de correção de fluxo, 803 Intensivo.

\section{Outro exemplo da presença de reportagem didática no Jornal 803} Intensivo é demonstrado abaixo: 


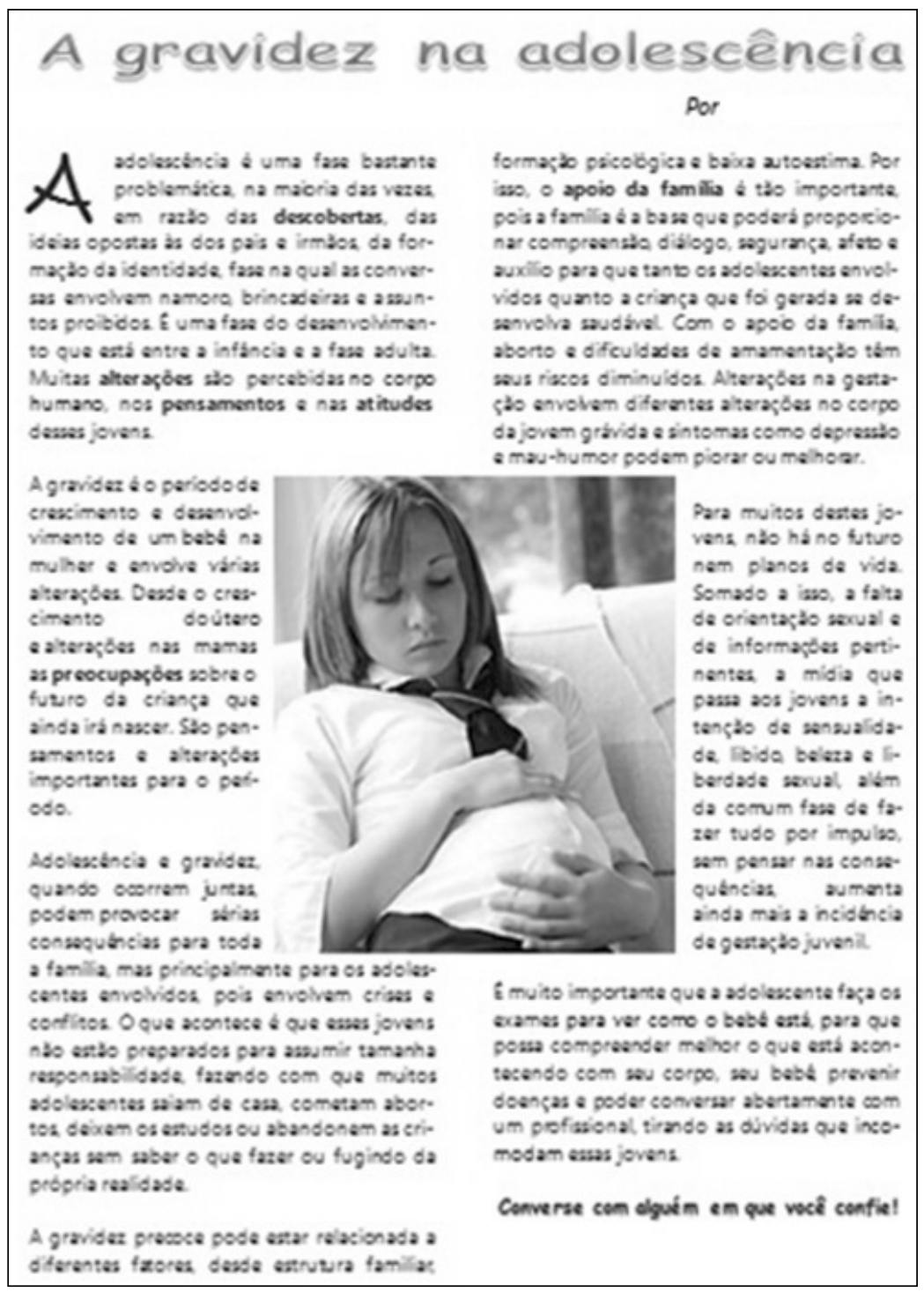

Jornal escolar

no ensino

fundamental

Figura 10 - Exemplo de reportagem didática publicada no Jornal 803 Intensivo; Fonte:

Reportagem didática publicada na página 3 da edição n. 1 do Jornal 803 Intensivo publicada em julho de 2012, pelos alunos da turma de correção de fluxo, 803 Intensivo.

Os três exemplos de reportagem didática podem demonstrar a presença constante do gênero em questão nas duas edições, tendo em vista que os textos publicados seguem os mesmos padrões.

Os aspectos destacados acima (os gêneros cabeçalho, expediente, notícia, reportagem e o elemento paginação) são frequentemente relacionados ao jornal (BONINI, 2008) e podem ser também relacionados ao 
jornal escolar analisado aqui. Agrupados numa mesma publicação, eles auxiliam a constituir uma unidade maior, o hipergênero jornal escolar. Esses elementos contribuem para que o jornal assuma uma organização textual específica, uma organização comum à maioria dos jornais.

\section{Análise crítica do jornal escolar}

Ao assumir o entendimento de jornal escolar como gênero e, tendo em vista que o gênero pode ser visto como "um conteúdo representacional Vanessa dinâmico que corresponde a uma forma característica de um texto sob a forma de enunciado" trago os elementos que determinam o enuncia-

Lima do para a discussão, como forma de corroborar a definição de jornal como gênero. Esses elementos são, segundo Bakhtin (2011/1953, p. 275):

a) "alternância dos sujeitos do discurso" e, b) a "conclusibilidade", que pode ser dividida em: "exauribilidade do objeto e do sentido", "projeto de discurso ou vontade de discurso do falante" e as "formas típicas composicionais e de gênero do acabamento".

Dessa forma, o jornal escolar caracterizado como enunciado, apresenta uma "alternância dos sujeitos do discurso", tendo em vista que o jornal escolar apresenta "um modo dixi que assinala a alternância de enunciados" e tendo em vista que este jornal escolar possui uma periodização semestral, isso permite que o outro (a comunidade escolar, por exemplo) se manifeste em relação ao seu conteúdo.

Quanto à conclusibilidade do enunciado, referente à "exauribilidade do objeto e do sentido", este é um aspecto que tende a se mostrar mais abertamente no jornal escolar. Se o jornal escolar é tomado como um enunciado produzido por uma "equipe que expressa todo o conteúdo que pode expressar naquela edição", é possível pensar na exauribilidade do objeto e do sentido, tendo em vista que é incomum que conteúdos sejam retomados em outras edições e porque, assim, o público consumidor do gênero jornal escolar pode manifestar sua atitude responsiva ativa e, assim, produzir reações que podem levar a novas produções ou à paralisação das publicações.

No que se refere ao "projeto de discurso do falante" no jornal escolar, neste caso, não se pode identificar um intuito através do enunciado, ou seja, dessas edições de jornal escolar. Apesar de ser uma característica esperada de um jornal, este jornal não apresenta uma linha editorial. Ao considerar que não há uma linha editorial clara e definida, seria possível caracterizar esse jornal como uma coleção de textos, en- 
tretanto, essa ausência de linha editorial não significa a ausência de um projeto de dizer. Talvez seja possível dizer que o projeto de dizer desse enunciado esteja relacionado muito mais à tentativa de fornecer alguma visibilidade à turma e a sua produção, que propriamente à função de definir um tema e discuti-lo frente à comunidade escolar.

Quanto às "formas típicas composicionais e de gênero do acabamento" no enunciado em questão, o que se espera de um jornal escolar é que esse apresente elementos que facilitem seu reconhecimento como tal. Esses elementos podem ser uma linha editorial (que representa o projeto de dizer da publicação), ou uma divisão por seções que organizam os textos (como esporte, polícia, comunidade), ou ainda, uma seção de carta do leitor. Alguns elementos podem ser encontrados nos jornais analisados, como o expediente, o cabeçalho, a notícia ou a reportagem. Jornal escolar no ensino fundamental Porém, é clara a ausência de seções, cadernos ou ainda, de chamadas que direcionem a atenção do leitor para o interior da publicação.

A ausência desses elementos evidencia que este jornal escolar é diferente do que se idealiza para uma produção desse tipo, mas essa ausência não é capaz de invalidar a caracterização deste jornal escolar como um gênero constituído por outros gêneros. Itens como o cabeçalho, a paginação, o expediente e a presença de notícias e reportagens são itens suficientes para caracterizá-lo como tal. Além disso, se há um projeto de dizer no enunciado, há um gênero sendo produzido e criando espaço para a circulação de outros gêneros.

Nesse sentido, se nestes jornais escolares existem aspectos capazes de propiciar sua configuração como gênero, também há aspectos ausentes sobre os quais é preciso refletir. Os motivos de essas duas edições de jornal escolar não se assemelharem à maioria das produções de jornal escolar estão relacionados ao contexto que envolveu a produção. Naquele momento, por influência das práticas sociais, essa foi a possibilidade de produção.

A produção deste jornal escolar esteve envolvida por práticas sociais que circundam não apenas a realidade local desses estudantes e suas histórias, mas também suas crenças (a de que não sabiam fazer, por exemplo), seus valores (influenciados por uma visão de mundo limitada a suas experiências com esse mesmo mundo) e essas influências se mostraram em sua "deficiente" produção de texto.

Quanto à ausência de uma linha editorial, por mais que um dos pontos pensados no projeto inicial fosse um trabalho com um jornal escolar que apresentasse uma linha editorial definida, com o andamento 
do projeto e a falta de engajamento dos estudantes ficou clara a dificuldade de definir uma linha editorial, impedindo que o gênero sofresse uma amarração, um acabamento idealizado para uma produção escolar com esta. A produção de textos não se configurou como uma produção de gêneros específicos para o jornal escolar, como tomar a produção de notícias ou de reportagens para as edições como um objetivo do projeto. Isso se deve também à visão que a própria turma tinha sobre si. Essa visão também influenciou na produção do gênero, fazendo com que o

Vanessa

Wendhausen

Lima projeto passasse por modificações.

Este jornal é diferente do que se espera de um jornal escolar por conta, também, da ausência do trabalho em grupo e da dificuldade em se formar equipes produtoras de textos. 0 trabalho pautado na produção individual influenciou no projeto de dizer do enunciado, haja vista que, por essa característica, o jornal poderia até ser caracterizado como uma coleção de textos. A prática de trabalhar individualmente é evidenciada nos textos produzidos por apenas um autor, quando uma equipe editorial poderia se responsabilizar pela produção do jornal como um todo.

Assim, o gênero jornal escolar sofreu influências oriundas tanto de práticas sociais externas, no que se refere às minhas falhas e às dificuldades apresentadas pelos estudantes de modo geral, quanto internas, quando o gênero não mostra claramente um projeto de dizer. A ausência de elementos que concretizam o jornal escolar como gênero, por exemplo, também é uma consequência da influência dessas práticas sociais. É possível caracterizá-lo como gênero porque outros gêneros estão presentes na produção, no entanto gêneros essenciais, como o editorial, por exemplo, fazem falta no momento de estabelecer um projeto de dizer para o enunciado.

\section{Considerações Finais}

A produção textual em sala de aula deve se configurar como uma forma de agir sobre o mundo em que se vive e permitir que o estudante saia da posição de receptividade que lhe foi imposta e consiga agir como protagonista em seu próprio aprendizado, levando-a a agir também dessa forma no mundo em que vive.

As influências pelas quais um gênero passa estão para além do expresso textualmente, isso porque o gênero está imerso em práticas sociais que lhe são inerentes e que determinam sua forma, seu conteúdo, a maneira como os sujeitos o (re)produzem e o compreendem. Essa relação 
dialógica é um fator constitutivo do gênero, evidenciando que um gênero está sempre conectado a outro, que uma prática discursiva está sempre ligada à outra, interferindo-se e influenciando-se mutuamente.

O objetivo deste trabalho era o de analisar, do ponto de vista da Análise Crítica de Gênero, a relação entre gênero e prática social em jornal escolar produzido por alunos de uma turma de correção de fluxo dos anos finais do ensino fundamental de uma escola pública estadual do município de Tubarão, SC. Essa produção, caracterizada como jornal escolar, apresenta características diferentes do esperado para uma publicação do tipo, porque as práticas sociais nas quais a equipe produtora estava envolvida influenciaram na constituição do gênero jornal escolar. Dessa forma, por mais que uma proposta de ensino de gêneros seja cuidadosamente planejada, o momento da produção genérica será

Jornal escolar no ensino fundamental influenciado pela prática social e essa, por sua vez, influenciará o projeto como um todo.

Ao entrar em sala de aula, o professor deve estar atento não só àquilo que se realiza nas aulas, mas às influências extraescolares e sociais como um todo. $O$ gênero é um exemplo de como a estrutura e a prática social influenciam indivíduos, mesmo produções textuais escolares.

\section{REFERÊNCIAS}

BAKHTIN, M. M. Estética da criação verbal. Trad. de Paulo Bezerra. São Paulo: Martins Fontes, 2011/1953.

BAZERMAN, C. Gêneros textuais, tipificação e interação. Trad. de Judith Chambliss Hoffnagel. São Paulo: Cortez, 2006.

BONINI, A. Em busca de um modelo integrado para os gêneros do jornal. In: CAVALCANTE, M. M.; BRITO, M. A. P. (Orgs.). Gêneros Textuais e Referenciação. Fortaleza: Grupo Protexto, 2001. (livro em cd-rom).

As relações constitutivas entre o jornal e seus gêneros: relato das pesquisas do "Projeto Gêneros do Jornal". In: BRAGA, Sandro et al (Org.). Ciências da linguagem: avaliando o percurso, abrindo caminhos. Blumenau: Nova Letra, 2008, p.21-45. 
- Mídia, suporte e hipergênero: os gêneros textuais e suas relações. Revista Brasileira de Linguística Aplicada, Belo Horizonte, v. 11, n. 3, p. 679-704, 2011.

FAIRCLOUGH, N. Discurso e mudança social. Trad. de Izabel Magalhães. Brasília: UnB, 2008/1992.

Analysing discourse: textual analysis for social research. LonVanessa don: Routledge, 2003.

Wendhausen

Lima LIMA, V. W. A prática social no jornal escolar: estudo do ponto de vista da análise crítica de gênero. 2014. Tese (2014) - Universidade do Sul de Santa Catarina, Tubarão.

SWALES, J. Genre analysis: English in academic and research settings. New York: Cambridge University Press, 1990. 